\title{
Language Analysis of E-C Translation of British and American Literature
}

\author{
Fuliang Wang
}

Hebei Academy of Fine Arts, Shijiazhuang, 050700, China

Keywords: British and American literature works, Literary translation, Mainland China, Taiwan, language differences, E-C translation texts

\begin{abstract}
Since the early 20th century, China has been input a large amount of foreign cultural. Many excellent British and American literature were translated, and outstanding translators such as Guo, Xiao Qian, Zhang Guruo, Wang Zuoliang built a bridge between Chinese and Western culture, making countless classic works well known by Chinese. After 1949, in Taiwan, local translators of British and American literaure Yu Guangzhong, Liang Shiqiu also showed upon the stage with feactures of Taiwan Mandarin. This paper analyzes the language differences of literature and grammar between Taiwan and Mainland China in E-C translation of British and American literature works through analysis of excellent translated texts, to seek for the fine point of language, arts and culture in Taiwan and Mainland China.
\end{abstract}

\section{Introduction}

Literary translation is painting rather than photographing. In other words, literary translation should be faithful to the original text and combine the target culture, giving a new cultural connotation and life to the British and American literature works, more similar in "spirit" than in

"form" . In analyzing the translation of Faust by Fulongqinke, the famous Russian writer Turgenev said that "even a translation has been made all kinds of favorable publicity before produced, it still has to attract audience through the quality, so that people will admire it as the original. Therefore, translator should be a genius in creation, aesthetics and talented. Translation is far more about strictness and earnestness. ${ }^{[1]}$ ”

\section{Connotation of E-C Translation of British and American Literature Work in Taiwan and Mainland China}

Huang Canran, a Translator in Hongkong mentioned that "the prosperity of translation is not motivated by the thirst for Western culture, but by the thirst for language vitality of Chinese." In this way, the language problem caused by E-C translation of British and American literature works should be explored from the perspective of difference. So that they can learn from each other, get more constructive experience.

The so-called difference is the direction of diversified development. But in the long run, the cultural diversity will eventually lead to polymerization. In this process, in Mainland and Taiwan, two big areas where Chinese language and culture are carried forward and inherited, cultures must be homological. Over the years, translators have been sought for the root and frequent cultural exchanges with efforts of generations. They hoped to break through the historical barriers by literature and culture, to bring back the opportunity of dialogue, so that people understand each other in exchange and cultural heritage, promote harmony, and finally to seek the unity of culture and ideology, to achieve the Chinese people' s unity. So in this paper the author, based on the British and American literature works, hopes to explore into the Chinese language culture, find the nature from difference, and seek for the beginner' s mind of Chinese language and culture. 


\section{Exchanges of E-C Translation of British and American Literature Work in Taiwan and Mainland China}

Due to historical reasons, Taiwan and the mainland have very different cultural development path and characteristics. Adopting the mainland writers' versions for nearly half a century later, translators in Taiwan began developing their own translation career in the late 1970s. They stopped taking reference and sharing with the mainland, and an influential generation of literary translators born. They are totally different from the mainland translators in understanding of the works, translation style, diction, and expressing. After the style analysis of two versions of Hemingway' $\mathrm{s}$ the old man and the sea, it is found that the version of the mainland translator Haiguan is a more literal one. The literal meaning of language is very close to the original, but the wording is slightly obscure and stiff. The version of Taiwan translator Song Biyun is more free. Her language is more life-based, and more conforms to the Chinese logic and rhyme. The text is more concise. However, the comparison is out of coincidence, cannot be generalized. Therefore, different E-C translation texts will be analyzed from comprehensive perspectives to explore various translation strategies adopted by the translators in two areas, as well as the Chinese language and culture features represented ${ }^{[2]}$.

\section{Wording and Rhetoric Difference in E-C Translation of Novels}

Chinese words and rhetoric is the foundation of Britsih and American Literature translation, concise language and accurate rhetoric and wording can promote literary conservation of translated texts, and even to the superior literary taste to the original text. This is a case study of the translation of A Tale of Two Cities, the late work of Dickens Charles, the famous British realistic writer. Through this case, the author explores the differences in wording and rhetorics in E-C translation in the mainland and Taiwan.

A Tale of Two Cities is an immortal masterpiece in the history of European literature, which describes the during fierce class antagonism and hierarchy conflicts during the French Revolution. All kinds of human nature are depicted, covering a wide and diversified range of people. But the whole writing style is simple and rigorous. The language is elegant and sharp, criticizing France and the European society at that time. It is such a famous work in China, and its Chinese versions are so varied, so here are two versions selected: one by Zhang Yang in the mainland, and the other by Wen Yihong from Taiwan in 2011.

\section{Differences in Wordings}

Generally speaking, translations in the mainland pay more attention to the expression of literary grace and gorgeous words, while Taiwan versions are relatively low-key, with economical wording and simple text structure.

Example 1: The curtains were long and white,and some of the thunder-gusts that whirled into the corner,caught them up to the ceiling,and waved then like spectral wings.

This is environment description with gorgeous wording and use of metaphor.

Taiwan version: 洁白的长窗窝被那吹到街角的风所掀起直到天花板上, 不断的飘荡着, 就 像幽灵的一双翅膀。

Mainland version: 窗帘洁白而悠长, 窗外的阵阵狂风夹杂着雷雨呼啸而过, 席卷了街角, 把窗帘猛的卷向了天花板上, 窗帘剧烈的上下扇动着, 就如同精灵鬼怪的双翼一般。

Obviously, the mainland translator slightly exaggerates the concrete world, even building a unreal world. Image thinking is widely applied to wordings. The stormy atmosphere is vividly portrayed and created by the description of actual scene, allowing readers to have the feeling of be personally on the scene, full of image. In grammar, the mainland translator also preserves the short phrase sentence in the original text. Descriptions of curtain is to render the gloom and terror atmosphere of night. From the extended perspective, the author hopes the reader can feel bloody turbulent brought about by the French Revolution that through the description of the environment, so the environment description is an example of highlighting the cultural and political environment of the original text. Of course, 
Taiwan version is more concise, without too much fancy words, and the curtains, the specter and wings are also mentioned, but it is slightly inferior to the mainland version in association.

\section{Differences in Rhetorics}

The mainland translators are experiential in retaining the original rhetorics. They stress the reflection of aesthetic value of the original literary texts. Taiwan translators pay more attention to creativity. They may will abandon metaphor, metonymy, rhetoric and parallelism in the original text, and refurbish the translation with their own language and culture, in order to fit with the local culture of Taiwan.

Normally, Taiwan version is relatively simple, plain, while the mainland version is not straightforward and obscure, making readers doubt. The mainland translator has more experience in preserving the Chinese language meaning and English originality. On the basis of this principle, they can go to pursue the aesthetic and cultural sense of language in literature, and highlight literariness. Taiwan version is of more innovative elements. Taiwan translators are more creative and better at controlling and manipulating the form of language. In this way, the fidelity of the original declines, and translations may even be caught in the "illusion of equivalence" in literary translation. However, they are more adapted to the modern reader's taste, and beneficial in the literature and cultural heritage.

\section{Differences in Language Styles in E-C Translation of Drama}

In British and American literature, drama is certainly a big highlight, both literary and performing. Drama translation techniques also has double standard. Drama translation better shows the translator' s literary attainments, attention, and word weighing. To reflect the unique readability and rigor of dramatic works, to follow the roles' sentiment changes, to be lifelike and convey the feelings in words, it is more difficult in translating drama than novels. So both in the mainland and Taiwan, British and American drama translation stress not only on grasping vocabulary, syntax and discourse structure, also the cultural issues. Only by being familiar with the cultural atmosphere of British and American drama, can the translation be expressive. Some versions has changed the content of drama, but it is harmless. The key is to reflect the charm of drama characteristics and let the reader feel the powerful appeal of drama culture by wording, in other exaggerating words, is to increase the performance of words. Here is a case study of two versions of An Ideal Husband by British playwright Oscar Wilde. Some excerpts from the two versions by Wen Xin from the mainland and Xu Guangzhong from Taiwan respectively are to be analyzed from the perspective of language style.

In general, drama translations in the mainland emphasize vague and general literal translation, while the Taiwan versions are of more emphasis on smooth and refined language, in favor of free translation. This is similar to novel translation.

Example 2:Mrs.Cheveley: "Romance should never begin with sentiment.It should begin with science and end with a settlement.”

The mainland version: 谢弗利太太: “浪漫的故事永远不应该从感情开始, 它应该开始于 科学与财产的授予。”

The Taiwan version: 薛太太: “风流韵事绝对不能从柔情开始, 这种事是要开始于精打细 算, 并且需要签字过户的。”

In this drama, Mrs. Cheveley is larcenous, lusty, avarice and scheming, a perfect villain created by Wilde. Both of the versions highlight her characteristics. In the mainland version, "Romance" is rendered into “浪漫” . From a literal point of view, there is no problem. But from the perspective of language and literature works, “浪漫” is commendatory, so it is not appropriate to describe Mrs. Cheveley. “风流韵事” in Taiwan version is more appropriate to describe Mrs. Cheveley” s dissipation. “开始于科学和财产的授予” is inappropriate either, as it is too rational and flat. “精 打细算” and “签字过户” vividly depict Mrs. Cheveley” s fickleness and money-worshiping, so that the translation language well bring out the drama performance. 
In the translation of British and American drama, the action of language must be emphasized, because it can be a vivid reflection of the body language and action language of characters, thus highlighting the characteristics. So translations in the mainland and Taiwan adjust dramatic language from one point, lines. you can understand many words not from the mouth of the characters, but expressed by lines. This is the action of language ${ }^{[3]}$.

\section{Conclusion}

This paper compares the differences in expression techniques and grammar techniques of literary translation in the mainland and Taiwan. The purpose is to promote the literature and cultural exchanges by the feelings of different language style and features. Of course, cultural limitations and particularity can be seen through the E-C translation in the two areas. For historical reasons, they cannot be got rid of in a short time. But one thing is certain, that is, in literary translation, the Chinese version and the translator should always follow the objective existence of history, and play the role of cultural diversity on the basis of this law. They should explore, interpret, understand and merge the culture from the perspective of different time and space, and receive and absorb the world literature and culture from their own "views" to form their own wealth. The author believes that literary translation of the two areas fully reflect the extensive and profound Chinese culture. We hope that this difference can be retained. We should reserve the different understandings of Chinese culture, strengthen exchanges, and learn from each other. This is the real power driving the E-C translation.

\section{References}

[1] Gao Peixin. Appreciation of Language Art in British and American Literature from Perspective of Cross Culture . Chinese Language Construction, 2013, 12(20).

[2] Zhang Jing. A study of the Chinese translation of Hemingway's style -- Taking The Old Man and The Sea" as an example. Journal of Jiamusi Vocational College, 2015, (4):70-71.

[3] Song Weiduo. On Language Differences of E-C Translation of British and American Literature in the Mainland and Taiwan. Fujian Normal University, 2013, 7-32. 